\title{
Genetic diversity in Tunisian horse breeds
}

\author{
Bayrem Jemmali ${ }^{1}$, Mohamed Mezir Haddad ${ }^{2}$, Nawel Barhoumi ${ }^{1}$, Syrine Tounsi ${ }^{1}$, Faten Lasfer ${ }^{2}$, \\ Amira Trabelsi ${ }^{3}$, Belgacem Ben Aoun ${ }^{2}$, Imen Gritli ${ }^{3}$, Soufiene Ezzar ${ }^{2}$, Abdelhak Ben Younes $^{3}$, \\ Mohamed Habib Ezzaouia ${ }^{2}$, Boulbaba Rekik ${ }^{1}$, and Hatem Ouled Ahmed ${ }^{3}$ \\ ${ }^{1}$ Laboratoire d'Amélioration et de Développement Intégré de la Productivité Animale et des Ressources \\ Alimentaires, Ecole Supérieure d'Agriculture de Mateur, Université de Carthage, Carthage, Tunisia \\ ${ }^{2}$ Fondation Nationale d'Amélioration de la Race Chevaline, Sidi Thabet, Tunisia \\ ${ }^{3}$ Laboratoire d'Analyse Génétique Animale, Institut de la Recherche Vétérinaire de Tunisie, Tunis, Tunisia
}

Correspondence to: Bayrem Jemmali (bornijemali@yahoo.fr)

Received: 14 July 2016 - Revised: 8 May 2017 - Accepted: 11 May 2017 - Published: 13 June 2017

\begin{abstract}
This study aimed at screening genetic diversity and differentiation in four horse breeds raised in Tunisia, the Barb, Arab-Barb, Arabian, and English Thoroughbred breeds. A total of 200 blood samples (50 for each breed) were collected from the jugular veins of animals, and genomic DNA was extracted. The analysis of the genetic structure was carried out using a panel of 16 microsatellite loci. Results showed that all studied microsatellite markers were highly polymorphic in all breeds. Overall, a total of 147 alleles were detected using the 16 microsatellite loci. The average number of alleles per locus was $7.52(0.49), 7.35(0.54), 6.3(0.44)$, and 6 (0.38) for the Arab-Barb, Barb, Arabian, and English Thoroughbred breeds, respectively. The observed heterozygosities ranged from $0.63(0.03)$ in the English Thoroughbred to 0.72 in the Arab-Barb breeds, whereas the expected heterozygosities were between $0.68(0.02)$ in the English Thoroughbred and 0.73 in the Barb breeds. All $F_{\mathrm{ST}}$ values calculated by pairwise breed combinations were significantly different from zero $(p<0.05)$ and an important genetic differentiation among breeds was revealed. Genetic distances, the factorial correspondence, and principal coordinate analyses showed that the important amount of genetic variation was within population. These results may facilitate conservation programs for the studied breeds and enhance preserve their genetic diversity.
\end{abstract}

\section{Introduction}

Biological diversity or biodiversity refers to variability in the hereditary characteristics in a species. The highest genetic diversity level, for a species or a population, offers the opportunity for animals to challenge harsh environmental conditions and cope over with climate change and global warming. The worldwide breeds or populations' sizes went through continuous fluctuations that mirror environmental variation and demographic population growth (Willi et al., 2006; Andrew et al., 2011).

Recent statistics of the Food and Agriculture Organization (FAO) reported that the populations of numerous domestic animals, especially horses, are in steady decline, with some already extinct, thereby affecting both interbreed (decline in the actual number of equine breeds themselves) and intra-breed (decline in the number of individuals) diversities (FAO, 2011). Horses' population sizes of the Tunisian breeds account for around 26000 heads, of which 14000 , 6000, 5000, and 1000 are Arab-Barb, Barb, Arabian, and English Thoroughbred breeds, respectively. There are also 40000 male and female mules (FNARC, 2015). These animals are generally used in the fantasia (traditional exhibition of horsemanship performed during cultural festivals), as well as in the equestrian sports. Appropriate conservation and sustainable management programs for the Tunisian equine breeds need comprehensive information about their genetic diversity and populations' structures. Concurrently, a high genetic diversity may indicate a genetic diversity hot spot, a tool for targeting conservation efforts in livestock species (Freeman et al., 2006; Khanshour et al., 2013). 
Native horse breeds in Tunisia have been playing key roles through history in agriculture, transportation, and leisure activities. These breeds are now facing major constraints due to harsh climatic conditions and poor management practices. Haddad (2015) reported that the first studbook for Tunisian equine breeds was established in 20 June 1896. There were a few studies on the genetic diversity in the Tunisian horse breeds. The first study aimed at assessing autochthonous Tunisian horse's genetic diversity and was published in 2014 (Haddad et al., 2014; Jemmali et al., 2015). These authors attempted to characterize genetic relationships within and among local breeds (Barb, Arab-Barb and Mogod Pony). A poor genetic diversity was revealed. In the present time, there are attempts to start breeding programs for horses. Pedigree and performance recording are underway. Artificial insemination is a common practice in HARAS of FNARC in the north of Tunisia. Cross breeding is also used to upgrade breeds and to satisfy breeders' demand. There are, however, no conservation programs for equine breeds.

Microsatellite markers have been widely used to assess genetic variability for different horse breeds (Karima et al., 2011). Genetic diversity studies within and among horse breeds analyzed using microsatellites have been conducted on French breeds (Moureaux et al., 1995), Polish breeds (Zabek et al., 2005), Austrian breeds (Druml et al., 2007), American breeds (Tryon et al., 2009), and Algerian breeds (Berber et al., 2014).

The objective of the study was to characterize the molecular structure, microsatellite polymorphism, and genetic distances among breeds and to draw the phylogenic tree for horse breeds in Tunisia.

\section{Materials and methods}

\subsection{Population samples}

A total of 200 blood samples were taken and tested from the four Tunisian horse breeds (Barb: BA; Arab-Barb: AB; Arabian: AR; and English Thoroughbred: PS). To ensure that each sample was representative of the respective population, a strict sampling strategy was employed and studbook was consulted. The origins and familial relationships of individual animals were considered and 50 samples were taken for each breed.

Analyzed animals were chosen according genealogical information and familiar relationship. Only individuals with different ancestral ascendance were sampled. In order to choose most genetic variability contributors, for each breed, male and female were randomly equally represented.

Genomic DNA was amplified using 16 microsatellite loci (Table 1). All analyzed individuals were registered in the Tunisian breed's studbook. Approximately $5 \mathrm{~mL}$ of veins blood per animal was collected aseptically in tubes containing ethylenediaminetetraacetic acid (EDTA, $0.5 \mathrm{mM}$, $\mathrm{pH}$ 8.0).

\subsection{DNA isolation and microsatellites selection}

Genomic DNA was extracted from total blood using Purelink $^{\mathrm{TM}}$ Genomic DNA Mini Kit (Invitrogen) following the manufacturer's protocol. A total of 17 microsatellite markers (Table 1) specific to Equus caballus were used in this study. All microsatellite markers are included in the panel recommended by the International Society for Animal Genetics for diversity studies and parentage verification. Alphabetical nomenclature was used for allele size designation in accordance with the International Society for Animal Genetics.

\subsection{PCR conditions and data recording}

Amplification of used microsatellites included an initial denaturation at $95^{\circ} \mathrm{C}$ for $15 \mathrm{~min}$, followed by 30 cycles of $30 \mathrm{~s}$ at $94^{\circ} \mathrm{C}, 90 \mathrm{~s}$ at $58^{\circ} \mathrm{C}$ annealing temperature, and $1 \mathrm{~min}$ at $72^{\circ} \mathrm{C}$. A final elongation step was carried out at $60^{\circ} \mathrm{C}$ for $30 \mathrm{~min}$. The amplified products were denatured with formamide $(8.3 \mu \mathrm{L})$, and Gene Scan-500LIZ $(0.3 \mu \mathrm{L})$ and PCR products $(2 \mu \mathrm{L})$ were detected by capillary electrophoresis using an ABI Prism 3130 DNA genetic analyzer (Applied Biosystems, USA). Size analyses of DNA fragments separated were performed with Gene Mapper software (Applied Biosystems, Ver. 4.0). The genotyping assays of microsatellites were performed in the laboratory of Animal Genetic Analysis of the National Institute of veterinary research in Tunis, Tunisia.

\subsection{Statistical analysis}

Collected molecular data were edited for possible genotyping errors due to null alleles, short allele dominance, typographic errors, and the scoring of stutter peaks. Genetic diversity within breeds, genetic variation, and relationships among breeds were assessed using different softwares. GenAlex 6.2 was used to calculate gene diversity indices for each breed population (Khanshour et al., 2013). Genetix software (version 4.04) was used to screen allelic frequencies and the number of alleles per locus. Observed heterozygosity (Ho), expected heterozygosity (He), and unbiased expected heterozygosity (UHe) were calculated across loci and populations (Berber et al., 2014) and the effective number of migrants per generation $\left(N_{\mathrm{m}}\right.$; Wright, 1969). Wright's $F$ statistics $\left(F_{\mathrm{ST}}, F_{\mathrm{IS}}\right.$ and $F_{\mathrm{IT}}$; Wright, 1965,1978$)$ in the form proposed by Weir and Cockerham (1984) were computed using the Genetix software. The different $F$ statistics look at different levels of population structure. $F_{\mathrm{IT}}, F_{\mathrm{IS}}$, and $F_{\mathrm{ST}}$ are the inbreeding coefficient of an individual relative to the total population, the inbreeding coefficient of an individual relative to the subpopulation, and the effect of subpopulations compared to the total population, respectively. All coefficients conform to the following equation: 
Table 1. Microsatellite sequences and length size.

\begin{tabular}{|c|c|c|c|}
\hline Loci & Microsatellite sequences & $\begin{array}{l}\text { Length } \\
\text { size (bp) }\end{array}$ & References \\
\hline AHT4 & $\begin{array}{l}5^{\prime}: \text { AACCGCCTGAGCAAGGAAGT } \\
3^{\prime}: \text { CCCAGAGAGTTTACCCT }\end{array}$ & $144-164$ & Binns et al. (1995) \\
\hline AHT5 & $\begin{array}{l}5^{\prime}: \text { ACGGACACATCCCTGCCTGC } \\
3^{\prime}: \text { GCAGGCTAAGGAGGCTCAGC }\end{array}$ & $126-144$ & Binns et al. (1995) \\
\hline ASB2 & $\begin{array}{l}5^{\prime}: \text { CCACTAAGTGTCGTTTCAGAAGG } \\
3^{\prime}: \text { CACAACTGAGTTCTCTGATAGG }\end{array}$ & $216-250$ & Breen et al. (1997) \\
\hline ASB17 & $\begin{array}{l}5^{\prime}: \text { ACCATTCAGGATCTCCACCG } \\
3^{\prime}: \text { GAGGGCGGTACCTTTGTACC }\end{array}$ & $87-129$ & Breen et al. (1997) \\
\hline ASB23 & $\begin{array}{l}5^{\prime}: \text { GAGGGCAGCAGGTTGGGAAGG } \\
3^{\prime}: \text { ACATCCTGGTCAAATCACAGTCC }\end{array}$ & $175-211$ & Lear et al. (1999) \\
\hline CA425 & $\begin{array}{l}5^{\prime}: \text { AGCTGCCTCGTTAATTCA } \\
3^{\prime}: \text { CTCATGTCCGCTTGTCTC }\end{array}$ & $226-246$ & $\begin{array}{l}\text { Eggleston-Stott } \\
\text { et al. (1997) }\end{array}$ \\
\hline HMS1 & $\begin{array}{l}5^{\prime}: \text { CATCACTCTTCATGTCTGCTTGG } \\
3^{\prime}: \text { TTGACATAAATGCTTATCCTATGGC }\end{array}$ & $170-186$ & Guérin et al. (1994) \\
\hline HMS2 & $\begin{array}{l}5^{\prime}: \text { CTTGCAGTCGAATGTGTATTAAATG } \\
3^{\prime}: \text { ACGGTGGCAACTGCCAAGGAAG }\end{array}$ & $222-248$ & Guérin et al. (1994) \\
\hline HMS3 & $\begin{array}{l}5^{\prime}: \text { CCATCCTCACTTTTTCACTTTGTT } \\
3^{\prime}: \text { CCAACTCTTTGTCACATAACAAGA }\end{array}$ & $148-170$ & Guérin et al. (1994) \\
\hline HMS6 & $\begin{array}{l}5^{\prime}: \text { GAAGCTGCCAGTATTCAACCATTG } \\
3^{\prime}: \text { CTCCATCTTGTGAAGTGTAACTCA }\end{array}$ & $151-169$ & Guérin et al. (1994) \\
\hline HMS7 & $\begin{array}{l}5^{\prime}: \text { TGTTGTTGAAACATACCTTGACTGT } \\
3^{\prime}: \text { CAGGAAACTCATGTTGATACCATC }\end{array}$ & $165-185$ & Guérin et al. (1994) \\
\hline HTG4 & $\begin{array}{l}5^{\prime}: \text { CTATCTCAGTCTTGATTGCAGGAC } \\
3^{\prime}: \text { СТСССТСССТСССТСТGTTCTC }\end{array}$ & $127-139$ & Ellegren et al. (1992) \\
\hline HTG6 & $\begin{array}{l}5^{\prime}: \text { GTTCACTGAATGTCAAATTCTGCT } \\
3^{\prime}: \text { CCTGCTTGGAGGCTGTGATAAGAT }\end{array}$ & $84-102$ & Ellegren et al. (1992) \\
\hline HTG7 & $\begin{array}{l}5^{\prime}: \text { CCTGAAGCAGAACATCCCTCCTTG } \\
3^{\prime}: \text { ATAAAGTGTCTGGGCAGAGCTGCT }\end{array}$ & $118-128$ & Marklund et al. (1994) \\
\hline HTG10 & $\begin{array}{l}5^{\prime}: \text { TTTTTATTCTGATCTGTCACATTT } \\
3^{\prime}: \text { CAATTCCCGCCCCACCCCCGGCA }\end{array}$ & $95-115$ & Marklund et al. (1994) \\
\hline VHL20 & $\begin{array}{l}5^{\prime}: \text { CAAGTCCTCTTACTTGAAGACTAG } \\
3^{\prime}: \text { AACTCAGGGAGAATCTTCCTCAG }\end{array}$ & $87-105$ & $\begin{array}{l}\text { Van Hearingen et } \\
\text { al. (1994) }\end{array}$ \\
\hline
\end{tabular}

$\left(1-F_{\mathrm{IS}}\right)\left(1-F_{\mathrm{ST}}\right)=\left(1-F_{\mathrm{IT}}\right)$.

The representation of the genetic relationships among tested populations was done using the principal component (PCA) and the factorial correspondence (FCA) analyses as implemented by GenAlex 6.2 and Genetix 4.04. The dendrogram was constructed using unweighted pair group method averages (UPGMA) based on Nei's (1972) genetic distances.

Structure software (Pritchard et al., 2000) was used to analyze the genetic structure of sampled animal. The best $k$ value corresponding with the number of subpopulation was estimated based on the method of Evanno et al. (2005).

\section{Results and discussion}

\subsection{Microsatellite markers}

All loci microsatellites used in this study were amplified successfully in analyzed individuals for the four breeds (ArabBarb, Barb, Arabian, and English Thoroughbred). Collected data showed no evidence for null alleles or scoring error con- 


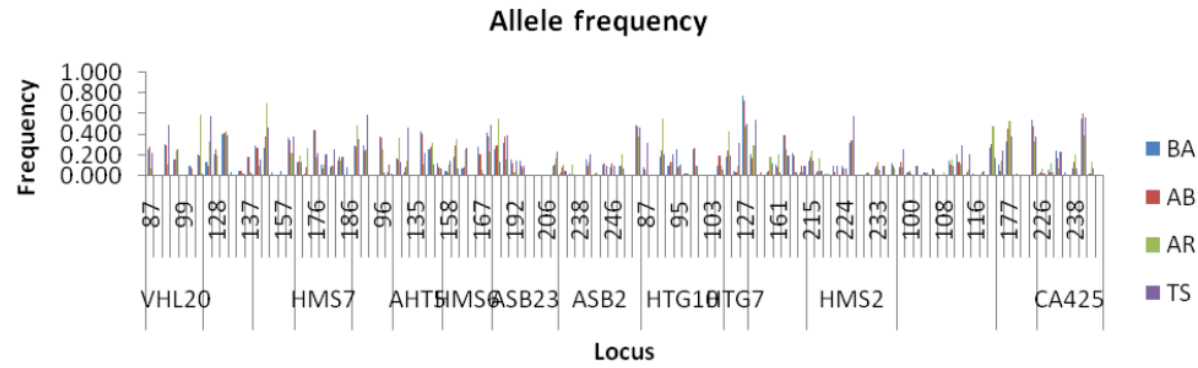

Figure 1. Allelic frequencies by population with graph over loci.

sidering all screened samples, although there were differences among tested samples with regard to presence or absence of alleles and their frequencies. All tested microsatellites were polymorphic in all populations. A total number of 147 different alleles were found across the 16 amplified loci. Allele frequency for analyzed data varied from 0.00 to 0.77 . The highest allelic frequency was observed for HTG7 (127 bp) with 0.77 and 0.72 for the Barb and ArabBarb breeds, respectively. Arabian and English Thoroughbred breeds had the highest frequencies for HMS1 (177 bp) and HMS2 (226 bp) with 0.58 and 0.64 , respectively (Fig. 1).

The number of effective alleles per locus indicates low or high genetic polymorphism richness of the used markers. The latter number ranged from 3.20 to 3.78 . This parameter was $3.78(0.31), 3.78(0.30), 3.41(0.25)$, and $3.20(0.22)$ in the Arab-Barb, Barb, Arabian and English Thoroughbred, respectively. Although values of the number of effective alleles in studied breeds were in comparable ranges, there is additional morphological variability (muzzle, nose, tail, mane, etc.) that can be detected by other parameters such as mean numbers of alleles per locus, observed heterozygosity, expected heterozygosity, and $F$ statistics.

\section{Genetic diversity within and among breeds}

The number of alleles per locus (Na) varied between 6 (HTG6, AHT6 and HMS1) and 13 (ASB23 and ASB17) with a mean of 9.31 (2.40) alleles. In Barb and ArabBarb breeds, comparable mean values were found for observed heterozygosity, expected heterozygosity, and unbiased expected heterozygosity. These values were $0.7(0.03)$, 0.73 (0.03), and 0.73 (0.03), respectively. For Arabian and English Thoroughbred breeds, respective values for Ho were respectively $0.65(0.04)$ and $0.64(0.03)$, for He they were $0.69(0.02)$ and $0.68(0.02)$, and for UHe they were 0.68 (0.02) and 0.68 (0.01). In all analyzed breeds we find Ho lower than He. When the observed heterozygosity is smaller than expected, it is because the mating has deviated from random mating-related individuals. Results of this study are similar to those reported by Solis et al. (2005), Khanshour et al. (2013) and Berber et al. (2014). Furthermore, Canon et al. (2000), Tozaki et al. (2003), Behl et al. (2007) and
Kusza et al. (2013) reported 6, 5.8, 5.2 and 6.6 as mean numbers of alleles per locus. However, Haddad et al. (2014) obtained 4.23 as a mean value in Barb and Tunisian Mogod Pony horse breeds.

The mean of the coefficient of inbreeding $\left(F_{\mathrm{ST}}\right)$ (Wright, $1969)$ was around $4.9(0.02)$ for all analyzed breeds. This result indicates a significant genetic variation between Tunisian horse breeds. Genetic differentiation among breeds was significant $(p<0.03)$ for all loci. The obtained results are comparable to those reported by Berber et al. (2014) and Haddad (2015). The latter authors confirmed the occurrence of genetic differentiation among North African autochthonous horse breeds. In the present study 32 private alleles were found. The number of rare alleles $(\mathrm{Np})$ was $10,7,7$ and 8 for $\mathrm{BA}, \mathrm{AB}, \mathrm{AR}$ and PS breeds, respectively (Table 2). Our results confirm findings by Berber et al. (2014) and Haddad (2015), especially for the North African Barb breed.

Mean $F_{\text {IS }}$ varied from -0.207 to 0.469 for AR, -0.205 to 0.565 for $\mathrm{PS},-0.156$ to 0.197 for $\mathrm{AB}$ and -0.115 to 0.112 for BA horses. This index reflects the Hardy-Weinberg disequilibrium especially for the Arabian and English Thoroughbred breeds. An important frequency of analyzed loci $(62.5 \%)$ showed positive values for $F_{\text {IS }}$. This result confirms that there was mating between relatives. Khanshour et al. (2013) reported similar disequilibrium results for the Arabian breeds.

The $F$ statistics and estimates of number of effective migrants over all populations are given in Table 3 for the four breeds of the study. The individual $F_{\mathrm{IS}}$ varied from -0.078 (AHT5 and HMS1) to 0.142 (HMS3). The $F_{\text {IS }}$ index was significantly different from zero $(p<0.05)$ only for the Arabian and English Thoroughbred breeds due to a lack of heterozygosity.

Wright (1978) reported that the $F_{\mathrm{ST}}$ indicates a moderate differentiation for values between 0.05 and 0.15 , a great differentiation for values between 0.15 and 0.25 , and an important genetic differentiation for values above 0.25 . Overall, $F_{\mathrm{ST}}$ values in this study suggest low genetic differentiation in all breeds. The $F_{\mathrm{ST}}$, in our case, ranged from 2.6 to $8.5 \%$ with an average of $5.5 \%(0.4)$. These levels for the $F_{\mathrm{ST}}$ in Tunisian horse breeds are smaller than those previously found in Algerian breeds ( $F_{\mathrm{ST}}=8.6 \%$, Berber et al., 2014), 
Table 2. Allelic frequency and heterozygosity for analyzed Tunisian breeds.

\begin{tabular}{llccccccc}
\hline Pop & & $\mathrm{Na}$ & $\mathrm{Ne}$ & $\mathrm{Ho}$ & $\mathrm{He}$ & $\mathrm{UHe}$ & $\mathrm{F}$ & $\mathrm{Np}$ \\
\hline \multirow{2}{*}{$\mathrm{AB}$} & Mean & 7.529 & 4.109 & 0.704 & 0.726 & 0.733 & 0.024 & \multirow{2}{*}{10} \\
& $\mathrm{SE}$ & 0.493 & 0.320 & 0.034 & 0.028 & 0.028 & 0.035 & \\
\hline \multirow{2}{*}{$\mathrm{BA}$} & Mean & 7.353 & 4.113 & 0.689 & 0.723 & 0.730 & 0.049 & 7 \\
& SE & 0.542 & 0.355 & 0.034 & 0.027 & 0.028 & 0.025 & \\
\hline \multirow{2}{*}{ AR } & Mean & 6.294 & 3.506 & 0.646 & 0.690 & 0.697 & 0.056 & 7 \\
& SE & 0.435 & 0.253 & 0.036 & 0.023 & 0.023 & 0.048 & 7 \\
\hline \multirow{2}{*}{ PS } & Mean & 6.000 & 3.434 & 0.636 & 0.684 & 0.691 & 0.068 & \\
& SE & 0.383 & 0.244 & 0.032 & 0.022 & 0.022 & 0.039 & 8 \\
\hline \multirow{2}{*}{ Total } & Mean & 6.794 & 3.791 & 0.669 & 0.706 & 0.713 & 0.049 & 8.25 \\
& SE & 0.242 & 0.150 & 0.017 & 0.012 & 0.013 & 0.019 & 1.5 \\
\hline
\end{tabular}

AB: Arab-Barb; BA: Barb; AR: Arabian; PS: English Thoroughbred; Np: private alleles.

Table 3. $F$ statistics and estimates of $F_{\mathrm{IS}}, F_{\mathrm{IT}}, F_{\mathrm{ST}}$ and $N_{\mathrm{m}}$ over all populations of the Tunisian horse breeds (AB, BA, AR and PS).

\begin{tabular}{lcccrrrrrrrrrrrrr}
\hline & VHL20 & HTG4 & AHT4 & HMS7 & HTG6 & AHT5 & HMS6 & ASB23 & ASB2 & HTG10 & HTG7 & HMS3 & HMS2 & ASB17 & HMS1 & CA425 \\
\hline$F_{\mathrm{IS}}$ & 0.059 & 0.080 & 0.081 & -0.014 & 0.063 & -0.078 & -0.031 & 0.072 & 0.045 & -0.002 & -0.078 & 0.142 & 0.024 & -0.025 & 0.087 & -0.065 \\
$F_{\mathrm{IT}}$ & 0.134 & 0.144 & 0.145 & 0.031 & 0.126 & 0.014 & 0.029 & 0.109 & 0.073 & 0.060 & 0.000 & 0.199 & 0.063 & 0.018 & 0.116 & -0.037 \\
$F_{\mathrm{ST}}$ & 0.080 & 0.070 & 0.070 & 0.044 & 0.068 & 0.085 & 0.058 & 0.040 & 0.029 & 0.062 & 0.072 & 0.066 & 0.040 & 0.041 & 0.031 & 0.026 \\
$N_{\mathrm{m}}$ & 2.885 & 3.335 & 3.314 & 5.421 & 3.434 & 2.683 & 4.058 & 6.026 & 8.290 & 3.782 & 3.201 & 3.528 & 6.040 & 5.775 & 7.727 & 9.463 \\
\hline
\end{tabular}

Polish breeds $\left(F_{\mathrm{ST}}=10 \%\right.$, Zabek et al., 2005), Brazilian breeds $\left(F_{\mathrm{ST}}=11.7 \%\right.$; Lippi and Mortari, 2003). However, they are slightly lower than the $6.5 \%$ reported by Behl et al. (2007) for five Indian horse breeds.

The numbers of effective migrants $\left(N_{\mathrm{m}}\right)$ exchanged per generation in all breeds are presented in Table 3. They show that the $N_{\mathrm{m}}$ values for all analyzed samples varied from 2.68 to 9.46. That number of effective migrants was very important especially for the Barb and Arab-Barb breeds (Tabe 3).

In total, 147 alleles were tested for the Hardy-Weinberg equilibrium (HWE) for all breeds. Significant $(p<0.05)$ deviations from the HWE were observed for $16(23.5 \%)$ of the 68 combinations. Only Arabian and English Thoroughbred horses exhibited significant deviation from the HWE $(p<0.04)$. The Arabian breed showed the maximum number of loci in disequilibrium (10 loci).

\subsection{Principal component analysis and spatial interpolation of the results}

The first three axes performed on allelic frequencies explain $63.48 \%$ of total inertia. Those first three axes explain $25.45,23.39$, and $14.64 \%$, respectively. The special distribution indicates high similarities between Barb and Arab-Barb breeds. A significant difference was observed between the Arabian and English Thoroughbred breeds (Fig. 2).

\subsection{Factorial correspondence analysis for analyzed horse breeds}

The factorial correspondence analysis as shown in Fig. 3 clearly differentiates the Barb, Arabian, and English Thoroughbred breeds. The Barb and Arab-Barb breeds were clustered together. The Arabian and the Arab-Barb breeds were also grouped together on another cluster with minor similarity compared to the first cluster. Berber et al. (2014) reported genetic proximity of both Barb and Arab-Barb breeds. These results corroborate those advanced by Ouragh et al. (1994). The neighbor-joining clustering approach and the factorial correspondence analysis were used as efficient tools that give precise information on breed relationships (Figs. 3 and 4). Genetic distances, the factorial correspondence, and principal coordinate analyses showed that the significant amount of genetic variation is within population.

\subsection{Structure analyses}

Estimated individual proportions of membership in each breed are represented by one cluster color. The ArabBarb (AB) and Barb (BA) breeds are clustered together. The English Thoroughbred (PS) breed was separated from the rest of populations. There are relative similarities between the Arab-Barb (AB) and the Arabian (AR) breed. 


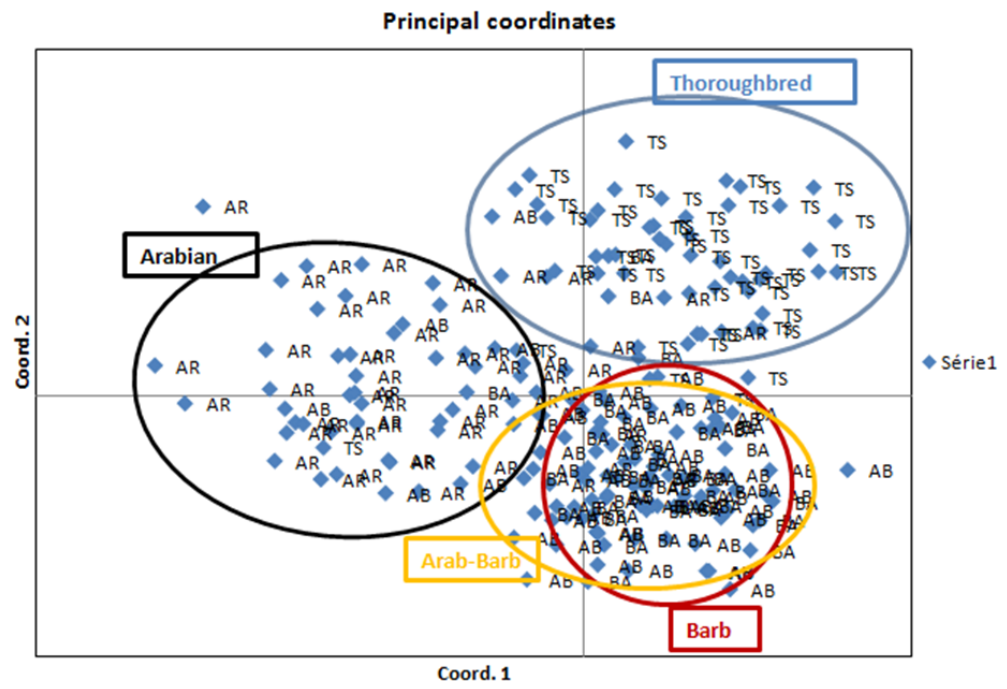

Figure 2. Principal component analysis for the Tunisian horse breeds.

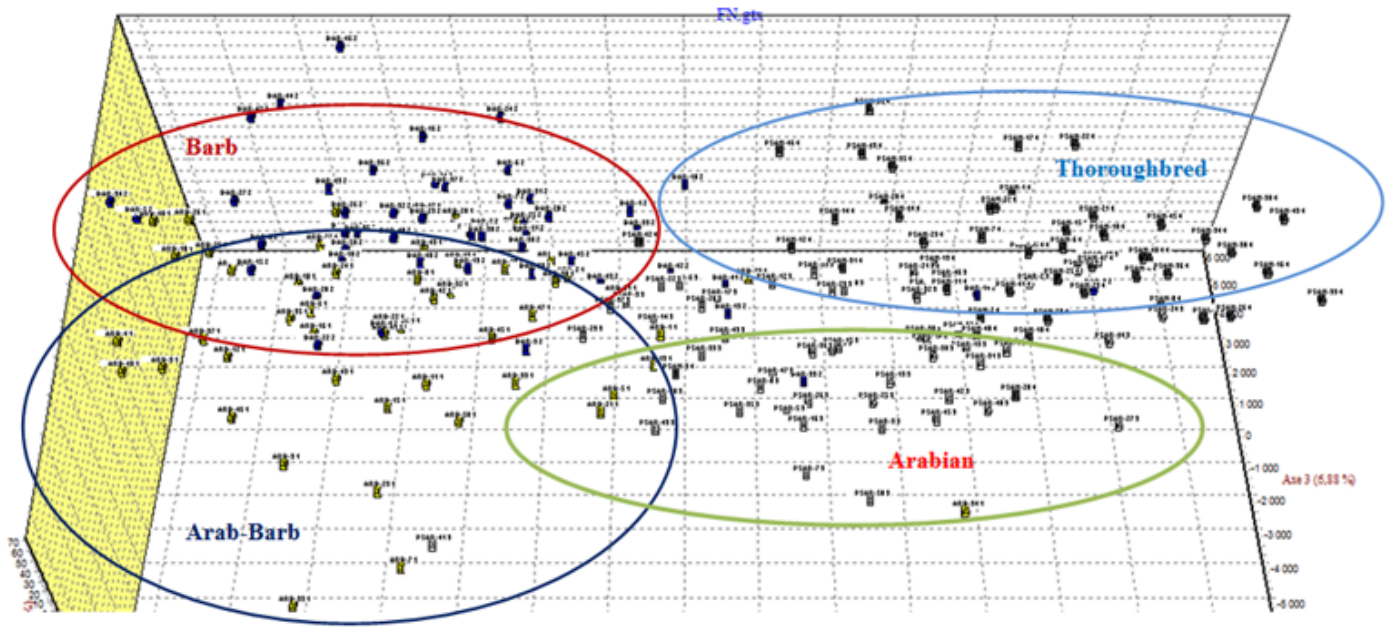

Figure 3. Factorial correspondence analysis for the Tunisian horse breeds.

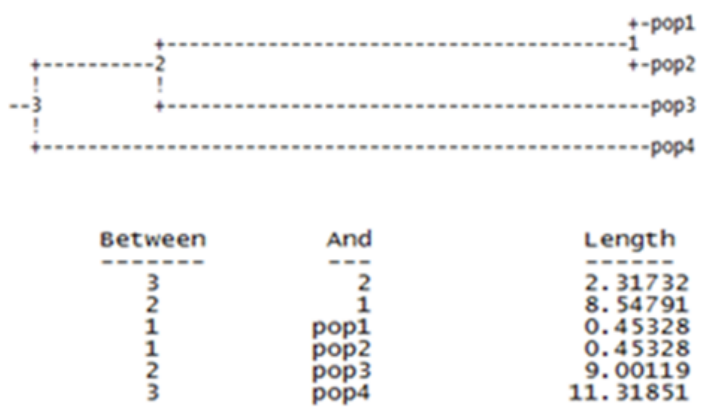

Figure 4. The neighbor-joining dendrogram including the four studied Tunisian breeds. AB: Arab-Barb (pop1); BA: Barb (pop2); AR: Arabian (pop3); and PS: English Thoroughbred (pop4).

\section{Conclusion}

This paper highlights the genetic structure of the Tunisian horse breeds. There is a genetic differentiation between Tunisian Barb and Arab-Barb horses and other breeds. The Barb and Arab-Barb appeared to be genetically similar and considered as the same group. This is can be explained by the continuous gene flow between both breeds. Furthermore, the significant amount of genetic variation was within populations. These results may help in the implementation of conservation programs of Tunisian horse breeds and enhance efforts to improve preserving revealed genetic diversity.

Data availability. The data used in the study can be obtained by email (Mezir Haddad, mezirhaddad@yahoo.fr) from the Fondation Nationale d'Amélioration de la Race Chevaline Sidi Thabet. 


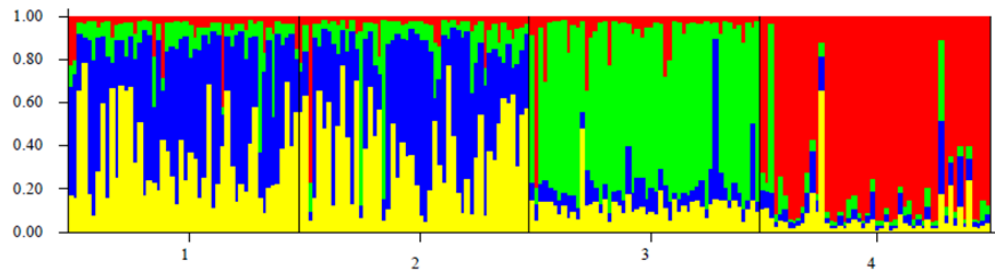

Figure 5. Graphical representation of membership of 200 individuals from AB: Arab-Barb (1); BA: Barb (2); AR: Arabian (3); and PS: English Thoroughbred (4).

Competing interests. The authors declare that they have no conflict of interest.

Edited by: S Maak

Reviewed by: two anonymous referees

\section{References}

Andrew, R. W., Carla, M. S., Andrew, G. Y., Richard, F., Nicki, J. M., Kim, A. M., Margaret, B., David, J. C., Mark, D. B. E., Paul, S., Martin, F. B., Elizabeth, A. J., and Ary, A. H.: Assessing the benefits and risks of translocations in changing environments: a genetic perspective, Evol. Appl., 4, 709-725, 2011.

Behl, R., Behl, J., Gupta, N., and Gupta, S. C.: Genetic relationships of five Indian horse breeds using microsatellite markers, Animal, 1, 483-488, 2007.

Berber, N., Gaouar, S., Leroy, G., Kdidi, S., Tabet, A. N., and Sardi Mehtar, N.: Molecular characterization and differentiation of five horse breeds raised in Algeria using polymorphic microsatellite Markers, J. Anim. Breed. Genet., 131, 387-394, 2014.

Binns, M. M., Holmes, N. G., Holliman, A., and Scott, A. M.: The identification of polymorphic microsatellite loci in the horse and their use in thoroughbred parentage testing, Brit. Vet. J., 151, 915, 1995

Breen, M., Lindgren, G., Binns, M. M., Norman, J., Irvin, Z., Bell, K., Sandberg, K., and Ellegren, H.: Genetical and physical assignments of equine microsatellites. First integration of anchored markers in horse genome mapping, Mamm. Genome, 8, 267273, 1997.

Canon, J., Checa, M. L., Carleos, C., Vega-Pla, J. L., Vallejo, M., and Dunner S.: The genetic structure of Spanish Celtic horse breeds inferred from microsatellite data, Anim. Genet., 31, 3948, 2000.

Druml, T., Curik, I., Baumung, R., Aberle, K., Distl, O., and Sölknet, J.: Individual-based assessment of population structure and admixture in Austrian, Croatian and German draught horses, Heredity, 98, 114-122, 2007.

Eggleston-Stott, M. L., Valle ADBautista, M., Dileanis, S., Wictum, E., and Bowling, A.: Nine equine dinucleotide repeats at microsatellite loci UCDEQ136, UCDEQ405, UCDEQ412, UCDEQ425, UCDEQ437, UCDEQ467, UCDEQ487, UCDEQ502 and UCDEQ505, Anim. Genet., 28, 438-440, 1997.

Ellegren, H., Johansson, M., Sandberg, K., and Andersson, L.: Cloning of highly polymorphic microsatellites in horse, Anim. Genet., 23, 1-9, 1992.
Evanno, G., Regnaut, S., and Goudet, J.: Detecting the number of clusters of individuals using the software STRUCTURE: a simulation study, Mol. Ecol., 14, 2611-2620, 2005.

FAO: Molecular genetic characterization of animal genetic resources, FAO Animal Production and Health Guidelines, No. 9 , Rome, 2011.

FNARC: Fondation Nationale d'Amélioration de la Race Chevaline, Rapport d'activité annuel, Sidi Thabet, Tunisie, 2015.

Freeman, A. R., Bradley, D. G., Nagda, S., Gibson, J. P., and Hanotte, O.: Combination of multiple microsatellite data sets to investigate genetic diversity and admixture of domestic cattle, Anim. Genet., 37, 1-9, 2006.

Guérin, G., Bertaud, M., and Amigues, Y.: Characterization of seven new horse microsatellites: HMS1, HMS2, HMS3, HMS5, HMS6, HMS7 and HMS8, Anim. Genet., 25, 62, 1994.

Haddad, M. M.: Caractérisation moleculaire de deux races equines autochtones: Le Barbe et Le Poney des mogods, Thse de Doctorat, Bibliothèque INAT, 159 pp., 2015.

Haddad, M. M., Jemmali, B., Bedhiaf, A., Bedhiaf, S., and Djemali, M.: Caractérisation moléculaire des races chevalines autochtones en Tunisie, Journal of new sciences, Agr. Biotechnol., 2, 11-20, 2014.

Jemmali, B., Haddad, M. M., Lasfer, F., Ben Aoun, B., Ezzar, S., Kribi, S., Ouled Ahmed, H., Ezzaouia, M. H., and Rekik, B.: Investigation de la diversité génétique des races Barbe et Arabe Barbe en Tunisie, J. New Sci. Agr. Biotech., 21, 830-838, 2015.

Karima, F. M., Hassanane, M., Abdel, M. M., Heba, I. S., and Nagwa H.: Genetic variations in horse using microsatellite markers, J. Genet. Eng. Biotechnol., 9, 103-109, 2011.

Khanshour, A., Conant, E., Juras, R., and Cothran, E. G.: Microsatellite analysis of genetic diversity and population structure of Arabian horse populations, J. Hered., 104, 386-398, 2013.

Kusza, S., Priskin, K., Ivankovic, A., Jedrzejewska, B., Podgorski, T., Jávor, A., and Mihók, S.: Genetic characterization and population bottleneck in the Hucul horse based on microsatellite and mitochondrial data, Biol. J. Linn. Soc., 54, 54-65, 2013.

Lear, T. L., Brandon, R., and Bell, K.: Physical mapping of ten equine dinucleotide repeat microsatellites, Anim. Genet., 30, 235, https://doi.org/10.1046/j.1365-2052.1999.00404-15.x, 1999.

Lippi, A. S. and Mortari, N.: Studies of blood groups and protein polymorphisms in the Brazilian horse breeds Mangalarga Marchador and Mangalarga (Equuscaballus), Genet. Mol. Biol., 26, 431-434, 2003.

Marklund, S., Ellegren, H., Eriksson, S., Sandberg, K., and Andersson, L.: Parentage testing and linkage analysis in the horse using 
a set of highly polymorphic microsatellites, Anim. Genet., 25, 19-23, 1994.

Moureaux, S., Ricard, A., Mériaux, J. C., and Verrier, E.: Caractérisation génétique des races françaises de sport et de course et analyse de leur variabilité génétique, 21 ème journée de la recherche équine, Les Haras Nationaux, Le Pin-au-Haras, 100-105, 1995.

Nei, M.: Genetic distance between populations, Am. Nat., 106, 283-292, 1972.

Ouragh, L., Meriaux, J. C., and Braun, J. P.: Genetic blood markers in Arabian, Barb and Arab-Barb horses in Mor-occo, Anim. Genet., 25, 45-47, 1994.

Pritchard, J., Stephens, M., and Donnelly, P.: Inference of population structure using multilocus genotype data, Genetics, 155, 945-959, 2000.

Solis, A., Jugo, B. M., Mériaux, J. C., Iriondo, M., Mazón, L. I., Aguirre, A. I., Vicario, A., and Estomba, A.: Genetic diversity within and among four South European native horse breeds based on microsatellite DNA analysis: implications for conservation, J. Hered., 96, 670-678, 2005.

Tozaki, T., Takezaki, N., Hasegawa, T., Ishida, N., Kurosawa, M., Tomita, M., Saitou, N., and Mukoyama, H.: Microsatellite variation in Japanese and Asian horses and their phylogenetic relationship using a European horse outgroup, J. Hered., 94, 374380, 2003.

Tryon, R. C., Penedo, M. C., McCue, M. E., Valberg, S. J., and Mickelson, J. R.: Evaluation of allele frequencies of inherited disease genes in subgroups of American Quarter Horses, J. Am. Vet. Med. Assoc., 234, 120-125, 2009.
Van Haeringen, H., Bowling, A. T., Stott, M. L., Lenstra, J. A., and Zwagstra, K. A.: A highly polymorphic horse microsatellite locus: VHL20, Anim. Genet., 25, 207, https://doi.org/10.1111/j.1365-2052.1994.tb00129.x, 1994.

Weir, B. S. and Cockerham, C. C.: Estimating $F$-statistics for the analysis of population structure, Evolution, 38, 1358-1370, 1984.

Willi, Y., Buskirk, J., and Hoffmann, A. A.: Limits to the adaptive potential of small populations, Annu. Rev. Ecol. Evol. System., 37, 433-478, 2006.

Wright, S.: The interpretation of population structure by $F$-statistics with special regard to systems of mating, Evolution, 19, 295420, 1965.

Wright, S.: Evolution and the Genetics of Populations. v. 2: The Theory of Gene Frequencies, University of Chicago Press, Chicago, 1969.

Wright, S.: Evolution and the Genetics of Poulations, in: Vol. 4, Variability Within end Among Natural Populations, Univ. of Chicago Press, Chicago, 1978.

Zabek, T., Nogaj, A., Radko, A., Nogaj, J., and Slota, E.: Genetic variation of Polish endangered Bilgoraj horses and two common horse breeds in microsatellite loci, J. Appl. Genet., 46, 299-305, 2005. 